\title{
Os Sentidos de Norma e Erro no Dicionário de Mattoso Camara Jr.
}

Pattern and Mistake Meanings in Mattoso Camara Jr.'s Dicionário

Phellipe Marcel da Silva ESTEVES*

Resumo: Joaquim Mattoso Camara Jr. foi, de acordo com diversas fontes, o primeiro linguista brasileiro, o primeiro a aliar gramática e ciências da linguagem no Brasil Não é, no entanto, da pessoa-Mattoso que trataremos aqui, mas das posições-sujeito ocupadas com seu nome na materialidade discursiva. Para isso, neste artigo, procuramos investigar, fundamentados no dispositivo teórico da Análise do Discurso Francesa (Pêcheux e Orlandi), os sentidos instituídos - na relação língua-classe social - no Dicionário de lingüística e gramática publicado por Mattoso. Veremos, entre outros aspectos, de que forma os estudos ditos metalinguísticos se inscrevem numa matriz de sentidos que legitima a língua como lugar de reflexo de hierarquia social, ajudando os futuros (e presentes) professores de língua portuguesa a compreender o fenômeno do preconceito linguístico por um viés discursivo.

Palavras-chave: Análise do discurso. Gramatização. Dicionários. Língua Portuguesa.

Abstract: Joaquim Mattoso Camara Jr., the first Brazilian linguist, the first to put grammar and language science together. It's not our aim to

${ }^{1}$ Os resultados apresentados neste trabalho foram fruto de pesquisa de mestrado intitulada $A$ translação de sentidos entre língua e classe social, desenvolvida na Universidade do Estado do Rio de Janeiro e contemplada por uma bolsa Capes.

* Mestre em Letras pela Universidade do Estado do Rio de Janeiro. Doutorado em andamento no Programa de Pós-Graduação em Estudos de Linguagem da Universidade Federal Fluminense. Contato: phellipemarcel@yahoo.com.br 
approach Mattoso as a person, but as the positions occupied by him in discursive materiality. For so, in this article, we intend to investigate, based on French Discourse Analysis (Pêcheux and Orlandi), the instituted meanings - in the relation language-social class - developed in the Dicionário de lingüistica e gramática published by Mattoso. It will be presented, among other things, in which way researchs known as metalinguistc are related to a Discursive Formation that allows the language to be a place that reflects the social hierarchy. In doing so, we hope future (and present) Portuguese teachers understand the phenomenum of linguistic prejudice in a discursive way.

Key-words: Discourse Analysis. Grammatization. Dictionaries. Portuguese.

\author{
por mais que diga \\ e porque disse \\ sempre restará \\ no dito o mudo \\ o por dizer \\ já que não é da linguagem \\ dizer tudo \\ (Ferreira Gullar)
}

Qualquer estudo sobre a língua se debruça sobre um objeto movediço, cujas características - em todos os sentidos - podem parecer transparentes, visto que a(s) língua(s) é(são) falada(s) em todo o mundo, então, cada falante julga-se um pouquinho conhecedor do código com que se comunica (e, ah, se o mistério terminasse no código e na comunicação... seria uma pena!). Esse transparente, segundo a Análise do Discurso com que optamos trabalhar, se alinha a um efeito ideológico: as características de uma língua, identificadas por um falante ou por um cientista, não são dados, mas fatos. Em outras palavras, qualquer conhecimento supostamente metalinguístico é produto de uma inscrição subjetiva em certos parâmetros de sentido. Nos termos de Pêcheux (2006), retomando a psicanálise de Jacques Lacan e retomado mais à frente por Jacqueline Authier-Revuz, não há metalinguagem porque toda tentativa de apreensão da língua é passível dos equívocos constitutivos de língua-sujeito. Sendo assim, uma das 
dificuldades dos estudiosos da língua - o critério para definição daquilo que é o certo, evitando o errado - necessariamente não corresponderá ao que de fato é, existe, mas ao que imaginariamente se pensa, se supõe. Nosso compromisso, neste artigo, é também produzir um saber sobre a língua, mas sabendo que estamos todos sujeitos (e dispostos, nesse caso) aos equívocos, e que nossa produção de conhecimento é interpretação, e não descrição pura e simples (como se ela fosse possível).

Para sanar a dúvida sobre o certo e o errado, os estudiosos recorrem a outros estudiosos legitimados (ORLANDI, 1996) na área de pesquisa. Mattoso Camara Jr. é um desses nomes, sempre autorbase da bibliografia dos cursos de Letras, sobretudo nas cadeiras de língua portuguesa e linguística, onde os alunos "aprofundam" seus conhecimentos exatamente sobre o que é certo e o que é errado. Interessados nesse público - discentes de cursos de Letras -, mas também nos próprios docentes, em sua prática de "correção da língua portuguesa", buscaremos entender não o que é o certo e o que é o errado em português, mas como os sentidos sobre essas noções vão sendo produzidos materialmente no fio discursivo no Dicionário de lingüistica e gramática.

Para o analista do discurso, dicionários e gramáticas são instrumentos de gramatização, tal como formulado por Auroux (1992), e necessariamente produtos de gestos interpretativos no discurso sobre a língua, numa subjetividade que (se) entende como normal - e normativa(os) - quanto às regras e quanto ao léxico. A partir dessa consideração, cabe nossa questão: Como se dá o funcionamento dos sentidos sobre variação, norma e erro que vão sendo articulados no Dicionário de lingüística e gramática de Mattoso Camara Jr. (1988; primeira edição, com o título Dicionário de filologia e gramática, de 1956)? Até que ponto, também, esses sentidos se atrelam aos sentidos de classe social, através principalmente das noções de variação e erro, sendo a norma já uma escolha de forma linguística e abstração da mesma?

\section{Da historicidade da normatividade contemporânea: condições de produção}

As gramáticas e dicionários são resultados de séculos de história de saber sobre a língua. Seu sentido nem sempre foi associado a um 
ditame de regras da "boa fala", do "bem escrever", mas culmina, atualmente, não exclusivamente no Brasil, mas também aqui, nesse destino. Politicamente, dois são os interesses enumerados por Auroux (2001, p. 47) para a gramatização de uma língua X: 1) organização e regulamento de uma língua literária; 2) pretensa expansão linguística interna e externa. É assim, gramatizado, que o português de Portugal é imposto ao Brasil a partir do século XVIII, como forma de expansão das fronteiras da nacionalidade através de um instrumento linguístico - daí ser resultado de uma política linguística colonialista (MARIANI, 2004).

No Brasil, depois de a colônia abolir a língua geral e a metrópole declarar a língua portuguesa obrigatória na colônia em meados do século XVIII, ${ }^{2}$ o Império Brasileiro, pós-independência, passa a exigir, em 1827, que os professores ensinem a gramática da lingua nacional (ORLANDI, 2005, p. 29), sem que se denomine essa língua como língua portuguesa (ou brasileira) nesse momento imediatamente posterior à Independência do Brasil, o que é reforçado por não haver ainda, no Brasil, gramáticas escritas por brasileiros, em nenhum molde. São as gramáticas de autoria portuguesa que circulam na ex-colônia, apesar da distinta historicidade entre o português da outrora metrópole a língua da ex-colônia. Não são apenas os portugueses que desembarcam no Brasil, mas também suas gramáticas, pautadas por um conhecimento metalinguístico pertinente à metrópole: ${ }^{3}$

${ }^{2}$ A transição tupi-português não ocorre de forma alguma automática e instantânea a partir da proibição da língua geral. Há resistência por parte de certos jesuítas, não sem punição da Coroa Portuguesa ou de seus representantes no Brasil (MARIANI, 2004). Como veremos à frente com a noção de heterogeneidade linguística formulada por Orlandi, o português adotado na colônia americana não é uma cópia ou continuação histórica linear do português europeu, mas constitui um diferente espaço de identidades subjetivas e sentidos.

${ }^{3}$ Não se deve confundir nossa teorização aqui com uma defesa da liberdade de autodeterminação do suposto povo brasileiro do século XIX através de gramáticas produzidas no Brasil propriamente. Argumentamos que as gramáticas que aqui chegam instituem uma ilusão de que a língua e o conhecimento metalinguístico portugueses e brasileiros são os mesmos, indistintos. No entanto, assim como analisaremos, mais à frente, o dicionário de Mattoso em sua defesa de uma noção de acerto que não corresponde à 
Ao mesmo tempo em que aqui desembarca, a língua portuguesa, ao deslocar-se de Portugal para o país nascente - o Brasil institui um movimento de memória, deslizamentos lingüísticos por meio dos quais uma outra língua - a brasileira - faz-se presente. O novo espaço de comunicação resiste com sua materialidade à língua que chega com os portugueses em sua memória já falada, já dita.

Desdobram-se, transmudam-se os modos de dizer. A relação palavra/coisa faz ruído, relação não coincidente entre si e nem perfeitamente ajustada. Outras formas vão estabelecer-se fazendo intervir, e ao mesmo tempo constituindo, a memória local. (ORLANDI, 2005, p. 29)

Há heterogeneidade linguística no caso da língua falada no Brasil, ou seja, o português da colônia possui um fundo falso, uma historicidade dupla, típica de línguas de países colonizados: "Essas línguas, o português e o brasileiro, filiam-se a discursividades distintas. O efeito de homogeneidade é o efeito produzido pela história da colonização" (ORLANDI, 2005). Talvez até mesmo por causa dessa heterogeneidade (o português europeu se configura como um "fundo falso" do português americano, o que promove essa aparente uniformidade), as gramáticas europeias circulem e vigorem no Brasil por décadas, até Júlio Ribeiro, em 1881, lançar sua Grammatica Portugueza. Minha tarefa não é a de recuperar, nunca, enquanto analista do discurso, o verdadeiro sentido, o significado primevo de tal enunciado ou de tal sequência discursiva (o que nem seria possível), mas a de estabelecer que relações e efeitos de sentido neles são promovidos, sempre ideologicamente. Portanto, ao ler o início do prefácio da Grammatica Portugueza: "As antigas grammaticas portuguezas eram mais dissertações de metaphysica do que exposições dos usos da língua" (RIBEIRO, 1884, p. 13 apud GUIMARÃES, 2004, p. 81), não leio as palavras de Ribeiro sobre as

fluidez linguístico-discursiva da língua falada no Brasil, sabemos que os instrumentos de gramatização portugueses também não dão conta dessa fluidez, simplesmente porque denotam uma norma e uma descrição sincrônicas que silenciam os equívocos constitutivos da língua. 
antigas gramáticas portuguesas (a que ele opõe sua obra, utilizando o adjetivo "antigas" e o pretérito imperfeito, referindo-se a um tempo que já se foi) como reflexo da verdade, mas entendo a Grammatica Portugueza se apresentando supostamente como inauguradora de uma abordagem nova sobre a língua: a de expor os usos da língua. Esses usos não correspondem à exposição da língua fluida do Brasil, mas correspondem a um gesto interpretativo sobre essa língua de forma a produzir uma língua imaginária nos discursos gramatical e dicionarísticos. É sobre essa tradição que o trabalho de Mattoso se firma: os usos expostos por ele serão escolhidos, nisso reside a problemática da variação e do erro. Como são eleitos esses usos que comparecem nas gramáticas brasileiras - introduzidas desde Júlio Ribeiro -, que já inauguram seus sentidos no Brasil sob uma vertente pedagógica inaugurada na Idade Média com as gramáticas monolíngues?- E que usos são esses?

Segundo Guimarães (2004), Júlio Ribeiro foi uma das figuras mais marcantes do segundo período dos estudos gramaticais na excolônia portuguesa, e estabeleceu uma data para o início da pesquisa da língua portuguesa no/do Brasil. A questão da padronização da língua e da descrição de um uso de caráter normativo já é uma preocupação de Ribeiro, e faz parte dessa tradição até, pelo menos, o que Guimarães considerará como o quarto período dos estudos da linguagem no Brasil (quando a linguística passa a figurar obrigatoriamente na grade curricular dos cursos de letras no país, conforme vimos ao final do capítulo 1). "A cena brasileira, então, inclui, de um lado, um novo pensamento lingüístico e mantém, de outro, a antiga e clássica concepção da gramática como arte de ensinar a falar e escrever corretamente (ou seja, como norma)." (GUIMARÃES, 2004, p. 35). Ainda segundo Guimarães, os autores desse período seguirão Mattoso Camara Jr., que de certa forma mantém o ideal de unidade de língua escrita entre a ex-colônia e a ex-metrópole - Brasil e Portugal. Daí este capítulo se debruçar sobre os escritos de Mattoso, e não sobre os de Júlio Ribeiro, embora identifiquemos como eles contribuíram para a formação de uma tradição gramatical brasileira. Também atentemos à dupla posição inaugurada na obra Mattoso: ao mesmo tempo que nela se inscreve um lugar de quem detém o conhecimento sobre a língua - como cientista, um dos primeiros linguistas estruturais 
brasileiros -, há também o lugar de quem exige regras, de quem demanda uma forma específica - o gramático normativo.

Este artigo se dedica à apreensão do funcionamento de sentidos sobre norma, erro e variação em Mattoso por conta de sua contribuição aos estudos da linguagem e sua figura - sua construção imaginária de precursor dos estudos linguísticos no Brasil. Tenho, assim, como intuito averiguar, com base na Análise do Discurso pecheutiana, os deslizamentos - "todo dizer, discursivamente, é um deslocamento nas redes de filiações (históricas) de sentidos" (ORLANDI, 2004, p. 61) -, as paráfrases (os "pontos de deriva possíveis" em Pêcheux, deslizes de sentidos), as repetições - "a repetição histórica, a que inscreve o dizer no repetível enquanto memória discursiva, saber discursivo" (ORLANDI, 2004, p. 70) - e mesmo a resistência em meus corpòra (de que partirei como sendo objetos linguístico-históricos (ORLANDI, 2004, p. 53)). Essas relações dos sentidos sobre variação linguística permitirão que analisemos de que forma determinado dizer se inscreve em certa formação discursiva ou se afasta dela, enquadrando-se em outra(s). As múltiplas conexões históricas que o discurso faz a outros discursos é que vão permitir seu sentido, é que vão indicar o "já-lá” e, por que não, o "sair de lá". Isso porque "na reprodução já há deslocamento, já há a não-reprodução: os sentidos reproduzidos em condições 'particulares' [...] podem ser carregados de outros sentidos, de transformações, de outros sentidos possíveis mas não ditos" (ORLANDI, 2007, p. 112).

É necessário, por isso, entender o que Orlandi chamará de resistência. Valendo-se da afirmação de Pêcheux de que "não há dominação sem resistência" e do conceito de refuncionalização (a contradição-transformação que resiste à burguesia, lidando com ela) formulado por Gramsci, Orlandi (1996) defende que, no jogo entre o mesmo e o diferente, este último é um sentido que está além do senso comum, dominado/dominante por/de toda a sociedade. Esse senso comum é definido pelos discursos hegemônicos historicamente, que nunca se desvinculam da ordem ideológica, da ordem da evidência. Assim, neste artigo, não será entendido o senso comum apenas como o ideário coletivo, uma "média" do pensamento moral, o consenso ou o senso natural - alguns dos sentidos que podem ser encontrados até nos dicionários -, mas como os sentidos circulados pelas formações 
discursivas - dentro de uma formação ideológica, ou seja, de uma visão de mundo determinada por uma prática política e ideológica de classe que torna os sentidos evidentes - dominantes. Relembrando o conceito de formação discursiva:

As formações ideológicas [...] comportam necessariamente, como um de seus componentes, uma ou várias formações discursivas interligadas, que determinam aquilo que pode e deve ser dito (articulado sob a forma de uma arenga, de um sermão, de um panfleto, de uma exposição, de um programa etc.) a partir de uma posição dada em uma determinada conjuntura. (HAROCHE; HENRY; PÊCHEUX, 1971, p. 102 apud SERRANI, 1997, p. 26)

Para avançar sobre as questões formuladas, a princípio depreendem-se sequências extraídas do Dicionário de lingüistica e gramática relativas ao binômio norma x erro, mostrando mais à frente as relações parafrásticas entre as definições de Mattoso e o imaginário de língua dos gramáticos contemporâneos. O discurso dicionarístico se constitui como espaço de definições cujos sentidos estão inscritos numa formação discursiva tal - e é a ela que pretendo chegar, verificando o que pode e deve ser dito no discurso dicionarístico. Fazem-se pertinentes, sabendo-se disso, as definições das categorias norma e erro no Dicionário de lingüística e gramática, já como sequências discursivas:

SD1: NORMA - Conjunto de hábitos lingüísticos vigentes no lugar ou na classe social mais prestigiosa no País. O esforço mesmo latente para manter a norma e estendê-la aos demais lugares e classes é um dos fatores do que se chama a correção (v.). A norma é contrariada pela variabilidade lingüística intrínseca, que se verifica - a) de um lugar para outro, b) de uma classe social para outra, c) de um indivíduo para outro. Do ponto de vista da norma, a variabilidade que a contraria constitui o ERRO, e temos, portanto, 3 espécies de ERRO: a) regionalismos (v.); b) vulgarismos (c.); c) erros individuais, que correspondem ao idioleto (v.). Todos esses três tipos de erros atuam contra a norma e tendem a enfraquecê-la ou modificá-la, principalmente 
quando na estrutura social se debilita o prestígio do lugar e da classe que representa. Assim, no Império Romano, o latim eclesiástico (v.), correspondendo à norma da aristocracia romana, cedeu lugar ao latim <<vulgar $>>$ com predominância dos vulgarismos e regionalmente diferenciado, além de favorecer a propagação dos erros individuais.

A norma é uma força conservadora na linguagem, mas não impede a evolução lingüística (v.), que está na essência do dinamismo da língua, como de todos os sistemas sociais (v. Dinâmica). Em muitas sociedades altamente evoluídas a norma se torna operante e agressiva, em face dos 3 tipos de Erro, por meio do ensino escolar e da organização de uma disciplina gramatical (v.)

V. registro (CAMARA JR., 1988, ${ }^{4}$ p. $\left.177-178\right)$ [negritos meus]

SD2: ERRO - v. norma; vulgarismo; idioleto. (CAMARA JR., 1988, p. 108) [negritos meus]

Entre outros aspectos, chama a atenção, num primeiro momento, a quantidade de remissões a outros verbetes que norma e erro trazem - em norma, remissão a "registro", mas também a "correção", "latim eclesiástico" etc.; em erro, remissão a "norma; vulgarismo; idioleto" -, sendo a definição de erro constituída basicamente de entradas remissivas. As remissivas funcionam dicursivamente como formas imaginárias de fixação de sentidos, mas não se trata apenas de uma forma de apagar os supostos sentidos não adequados à definição, conforme se poderia dizer. Duas posições aqui nos lembrarão de que há sentidos em fuga e que existe também um controle imaginário, ilusório de sentidos (cuja formulação se dá no plano linguístico por

${ }^{4}$ A data de 1988 foi a observada na edição usada para o trabalho, já intitulada Dicionário de lingüística e gramática. Esse título tem sua primeira impressão em 1977, mas em edições anteriores o livro se chamou Dicionário de fatos gramaticais (1956) e Dicionário de filologia e gramática (1964). Dias (2009, p. 56) se interessa por esse movimento de reintitulações em virtude do fato de questionar "a relação do título com a história". 
diversos recursos, no caso específico, o uso de remissivas): antes, e sobretudo, a de Pêcheux, Haroche e Henry (2008), que teorizam: “as palavras podem mudar de sentido segundo as posições determinadas por aqueles que as empregam"; e depois a de Authier-Revuz (1998), que determina que, embora as palavras sejam polissêmicas (graças mesmo ao interdiscurso), muitas vezes o funcionamento do discurso, por questões ideológicas, torna um sentido dominante, contudo, através de glosas e outros artifícios que são encontrados no fio discursivo, pode-se entrever a multiplicidade de sentidos que ora são postos em controle, ora são evitados - não intencionalmente. Ainda lançamos mão da noção de heterogeneidade enunciativa, segundo a qual há ocasiões em que o enunciador desdobra suas palavras sobre si mesmas, tentando com isso apagar, fixar, adicionar, modificar ou mesmo anular os $n$ outros sentidos que elas possuem. Dessa forma, num espaço das necessidades imaginárias (coerência, coesão, progressão etc.), o escritor busca fechar as palavras, dar uma conclusão a cada texto, e também concluir o sentido das palavras (ORLANDI, 2001).

A grande quantidade de referências feitas por Mattoso a outros verbetes funciona discursivamente de três formas distintas - que geram três efeitos distintos:

1) Controle imaginário de sentidos que podem se encontrar de alguma forma com os estudos da linguagem anteriores ou posteriores a Mattoso. Dessa forma, os sentidos circulantes entre as diferentes remissivas do texto de Mattoso vão definindo quem é o sujeito que ocupa o espaço/posição discursivo(a) do "discurso do saber sobre a lingua" (MORELLO, 2001, p. 19), dando-lhe estatuto científico. Dessa forma, ao tratar como único exemplo do verbete NORMA o "latim eclesiástico" e fazer remissão a ela, o Dicionário de lingüistica e gramática se aproxima de um exemplário formado pelas línguas tomadas como clássicas e aproxima essas línguas clássicas da noção de norma.

É nesse rumo que correção, regionalismos, idioleto, disciplina gramatical vão sendo conclamados a serem lidos em continuum ou durante a leitura do verbete NORMA. Eles serão demarcadores de sentidos apresentado ao leitor, que depende da compreensão desses mesmos sentidos para elaborar qualquer discurso do saber sobre a língua portuguesa válido, legítimo/legitimado. O sentido de variedade, bem como de qualquer 
outra palavra e dizer, passa por essa memória de tudo o que tal palavra, tal dizer já significou, isso atrelado à posição enunciativa e à instituição que será responsável pela veiculação dos discursos.

2) Defesa imaginária contra um sentido que pode parecer o único, como é o caso da remissão ao verbete evolução linguística, que figura na definição de NORMA: "A norma é uma força conservadora na linguagem, mas não impede a evolução lingüística (v.)". Ao se ler a definição do verbete EVOLUÇÃO LINGUÍSTICA, temos as seguintes palavras: "o caráter paulatino e gradual das mudanças [...] é inegável para muitas mudanças na língua e por isso o uso do termo se justifica, despojada em lingüística a sua significação da noção de crescimento ou progresso" (1988, p. 113) -, podemos verificar que discursivamente ocorre uma ilusão de contenção dos sentidos que poderia comprometer o ideal científico da linguística. Seriam os sentidos indicados no verbete: "crescimento ou progresso". Embora o termo "evolução" também se enquadre numa historicidade científica que o autor cita anteriormente, a da biologia do século XIX, que suscita sentidos de "crescimento ou progresso" a "evolução", esse sentido ameaça o caráter linguístico do termo.

A definição de evolução linguística, dessa forma, na tentativa ilusória de controlar os sentidos e excluir o sentido indesejado, traz uma glosa de fixação de sentido pela negação - que destaquei em negrito -, dando abertura ao transborde de outros sentidos. Authier-Revuz (1998) traz uma forma dessa glosa como "X, não no sentido de q". $\mathrm{Na}$ definição de evolução linguística, temos “[evolução], despojada ${ }^{5}$ em lingüística a sua significação da noção de crescimento ou progresso". Sendo assim, chegamos a uma glosa "só na forma negativa", que, segundo Authier, "elimina a ameaça do sentido q e aponta para a construção contextual de um sentido p para $\mathrm{X}$, que pela explicitação é colocado como complementar de q no conjunto de sentidos de X" (AUTHIER-REVUZ, 1998, p. 31-32). Assim, qualquer

\footnotetext{
${ }^{5}$ Entendemos "despojada [...] sua significação" aqui como uma negação, no mesmo formato de "não no sentido de".
} 
que seja o sentido de "evolução linguística" no dicionário que estamos analisando, ele é complementar da noção de "crescimento ou progresso". Numa relação interdiscursiva, a SD1 volta a esses sentidos de evolução como "crescimento ou progresso", quando Mattoso se refere a "sociedades altamente evoluídas", que combatem agressivamente os três tipos de erro que foram categorizados, a saber: regionalismos, vulgarismos, erros individuais.

3) Proteção ilusória contra a não contradição, no caso da definição de ERRO. Se a variabilidade que contraria a norma é o erro - "A norma é contrariada pela variabilidade lingüística intrínseca" - faz parte da necessidade ilusiva de coerência do texto (ORLANDI, 2001) um mecanismo que advogue a favor do sentido contínuo e progressivo, sem impasses à frente. Contudo, no caso específico do verbete ERRO, apresenta-se uma descontinuidade no que diz respeito à tipologia das variabilidades que, ao se oporem à norma, constituem erro. $\mathrm{Na}$ $\mathrm{SD} 1$, elas seriam os regionalismos, os vulgarismos e os idioletos. $\mathrm{Na}$ SD2 - "ERRO - v. norma; vulgarismo; idioleto." -, apenas vulgarismos e idioletos são contemplados, deixando regionalismos de lado. ${ }^{6} \mathrm{O}$ quadro seria o seguinte:

Quadro 1 - Falha no continuum da constituição de sentidos sobre erro nos verbetes NORMA e ERRO

No verbete NORMA a que

categorias linguísticas são associados

os sentidos de erro?

Regionalismo

Vulgarismos

Erros individuais
No verbete ERRO, quais são as remissões que ilusoriamente trabalham fixando seu sentido?

Vulgarismos

Idioletos (erros individuais)

${ }^{6}$ A Análise do Discurso não busca, com essa tentativa de compreensão do funcionamento do discurso, mapear os sentidos originais do autor ou acusá-lo de corromper um delirante sentido correto segundo a linguística e os ideais científicos. O como os sentidos vão surgindo (e sendo surgidos, nunca fortuitamente, sempre ideologicamente) é o que nos interessa. 
Essa descontinuidade - em que o regionalismo ora é erro e ora é deixado de fora - constitui duas posições discursivas em conflito, uma que remete os sentidos de variação social e individual aos de erros, e outra que inclui nesses sentidos de erro, além das duas variações anteriores, os regionalismos.

Ainda sobre o terceiro funcionamento: embora a definição de norma se caracterize por tipificar os erros possíveis e contrários ao suposto "conjunto de hábitos lingüísticos vigentes" (SD1), há em algum nível uma concentração, uma ênfase, no erro denominado vulgarismo conforme discursivizado no dicionário. Isso se dá não apenas no verbete ERRO, mas em NORMA, quando do único exemplo de modificação de uma norma: a substituição do latim eclesiástico pelo latim $<<$ vulgar $>>$, a que se submeteriam, ainda, variedades regionais, que sempre favoreceriam os erros individuais. Os sentidos de vulgarismo, ligados a classe social, também comparecem no esclarecimento "Todos esses três tipos de erros atuam contra a norma e tendem a enfraquecêla ou modificá-la, principalmente quando na estrutura social se debilita o prestígio do lugar e da classe que representa" [negritos meus]. Sendo assim, a categoria erro no dicionário de Mattoso funciona discursivamente vinculada aos sentidos de sociedade, visto que passa pela variação social.

Do mesmo Mattoso Camara Jr. é o artigo "Os estudos de português no Brasil” (2004). Ao longo das páginas, ao diferenciar língua popular de língua literária, a primeira é associada a sentidos de desregramento, assistematismo. Língua popular também é colocada em relação de sinonímia com "língua oral":

SD3: O problema das relações entre a língua popular e a língua literária é fundamental num caso como o brasileiro.

Tem de haver necessariamente uma diferenciação entre elas, decorrente das condições diversas em que se realizam. A língua oral opera numa situação concreta una entre os interlocutores, e os elementos extralingǘsticos se incorporam espontaneamente nessa situação. Daí o laissez-allez da fala, o seu aspecto fragmentário e a imprecisão dos termos e da construção frasal. Há ainda a considerar que no intercurso cotidiano impera o centrifugismo em face da norma, enquanto a língua literária é naturalmente centrípeta, com pontos de referência normativos 
muito claros e constantes. Acresce, finalmente, o assunto da comunicação, que na fala cotidiana é concreto e particular, de curto alcance intelectual e intenção estética, quando não intelectualmente vazio e esteticamente amorfo. (CAMARA JR., 2004, p. 253)

O termo laissez-allez remete historicamente a um enunciado de ideário liberal, retumbando inclusive a política de não intervenção estatal na economia do século XVII, o laissez-faire. Ao longo de SD3, a língua popular-oral/fala - três sintagmas nominais que ocorrem parafrasticamente - se distancia cada vez mais do que em Mattoso vai se constituindo como norma, e também se transforma em antônimo do ideal estético e intelectual da língua literária. Os conceitos de vulgarismo e de vocábulos populares significam na mesma formação discursiva que entende norma como contrária a esses conceitos, como ideal literário. Ambas as manifestações linguísticas devem, no dicionário de Mattoso, ser evitadas, por sua distância em relação ao ideal culto:

SD4: POPULARES - [...] dentro da sincronia, chamam-se populares as palavras próprias da língua popular e evitadas no uso culto adstrito a uma norma linguística (v.). (1988, p. 195)

SD5: VULGARISMO - Qualquer traço lingüístico do uso da língua nas classes populares, que diverge da norma (v.) [...] serve de índice de incultura e de nível intelectual baixo [...] (1988, p. 244) [negritos meus]

Vão-se, pouco a pouco, não apenas desqualificando as línguas e variedades diferentes da norma eleita como culta, como também os grupos sociais que as usam, uma vez que são eles, no discurso dicionarístico, incultos e de baixo nível intelectual. Está em jogo a classe social que imaginariamente, na formação discursiva que inscreve os sentidos produzidos e circulantes no Dicionário de lingüística e gramática, se correlaciona às variedades linguísticas. Quando norma, em SD5, não é acompanhada de nenhum adjunto adnominal, também nos perguntamos se existe apenas uma norma no dicionário de Mattoso, e se é esse o sentido sendo construído sobre norma. Sim. Conforme a 
SD1, a norma é o - e muita atenção a esse singular - "Conjunto de hábitos lingüísticos vigentes no lugar ou na classe social mais prestigiosa no País" -, e é apenas no lugar ou na classe, não havendo possibilidade de concomitância. A função do vulgarismo, segundo sua definição, é uma: servir como um indice de inferioridade.

O Dicionário de lingüística e gramática manifesta uma tensão de sentidos comentada por Agustini (2004): estar entre duas posições distintas e que se confundem na gramatização brasileira; linguista e gramático:

A instituição do curso de Letras a partir da década de 30 e o advento da lingüística imprime novos rumos à gramática que passa a se restringir à questão da norma e do ensinoaprendizagem da língua nacional, enquanto a lingüística fica com a autoridade para dizer como a língua funciona (ORLANDI, 1999). Esse deslocamento dos lugares (des)autorizados ao estudo e/ou ao ensino-aprendizagem da língua reforça o modo de dizer da ciência que a gramática toma para si e que configura uma tessitura enunciativa que não separa ciência e normatização da língua, isto é, política lingüística. A gramática somente é uma gramática porque não cai no cientificismo, porque não se reduz a uma análise lingüística, mas se produz por uma poética da adição de contraditórios. Poética essa que desloca o autor, ora ao lugar social de locutor gramático (normatizador), ora ao lugar social de locutor cientista da linguagem (na atualidade, o lugar social de locutor lingüista), ora ao lugar social de locutor professor (didatizador), decorrendo da relação desses lugares sociais de locutor a complexidade enunciativa da gramática e a sua tessitura enunciativa que recobre diferentes discursividades. (p. 59) [grifo meu]

Considero que essa mesma poética afeta as gramáticas de Bechara, Lima e Cunha (com Cintra) - que foram analisadas em minha pesquisa, embora esse tópico não seja apresentado aqui -, mas a relação dos sujeitos com os sentidos já em circulação em Mattoso garantirá diferentes e outros sentidos e articulações em cada uma, ainda que, veremos, possam todas fazer parte da mesma formação discursiva em que se inscreve o dicionário de Mattoso. 
O Dicionário de lingüistica e gramática ocupa um duplo espaço, talvez um prenúncio da tradição dos estudos gramaticais no Brasil, e certamente parte de sua memória discursiva. Além de estar posicionado como discurso do saber sobre a língua, a obra se destaca como instância de discurso do saber sobre o saber linguístico, servindo ora como prática político-linguística de conhecimento da língua, ora como legitimadora crítica do que é e do que não é científico ao se adentrar no campo do conhecimento dessa mesma língua. A distinção entre esses dois espaços discursivos é tratada por Morello (2001, p. 19-20):

Penso esse espaço [o do saber sobre o saber linguístico] como aquele de constituição de uma memória discursiva sobre o conhecimento e seus sujeitos que, inseparável dos outros dois, sobre eles incide, no entanto, sob a forma de refluxo de sentidos que afloram entre o que neles se torna ou não possível dizer. Ou seja, esse é um espaço de legitimação dos discursos sobre o saber, de sua forma e temas, e das condições básicas para sua validação ao mesmo tempo, é o espaço por meio do que se representam as relações de força e de dominação que caracterizam as práticas políticas institucionalizadas de produção do saber.

No dicionário de Mattoso, os sentidos de variabilidade contrariam os de norma. Mas isso permanece no Quarto Período sobre o qual Eduardo Guimarães fala em seus estudos, a partir da institucionalização da linguística como disciplina nas faculdades de Letras? E, se permanece, como permanece? É necessária uma reflexão sobre esses sentidos em algumas gramáticas, daí termos nos feito questões a respeito da construção de sentidos de variedade/norma nas gramáticas. Dessa forma, buscamos compreender como os sentidos de variação podem ter, ou não, se deslizado, mediante inclusive a entrada de outros discursos que corroboram o gramatical.

\section{A efeito de fechamento (só efeito)}

Verificamos haver um deslizamento dos sentidos de norma linguística e de erro linguístico para os de classe social. O dicionário de 
Mattoso, quando trata dos erros, ou seja, daquilo que Zoppi Fontana (1999 apud AGUSTINI, 2004) chama de mau comportamento linguístico, não apenas empreende uma cristalização dos sentidos de língua, mas também de classe social: haveria, segundo esse dicionário de Mattoso cujos verbetes acabamos de analisar, uma língua superior, assim como existe uma classe social superior correlata a esta mesma língua e contrária, oposta, a uma classe social inferior, correlata não a uma língua, mas a um erro linguístico, comportado pela variação linguística social.

Para Orlandi (2004, p. 39), "algo fala sempre antes, em outro lugar e independentemente [...]. É isto que fornece a cada sujeito 'a sua "realidade" enquanto sistema de evidências e de significações percebidasaceitas-experimentadas"'. De que forma o dicionário de Mattoso, ao fazer parte dessa rede de sentidos pré-existentes, ao já-dito, à evidência que garante que as palavras dos gramáticos signifiquem de antemão, está relacionado com as gramáticas que, segundo Guimarães, se alinham ao ideal de unidade linguística Brasil-Portugal tal como Mattoso? Também nas gramáticas contemporâneas circulam sentidos de variedade (principalmente os socioletos) como língua inferior pertencente a uma classe social inferior, enquadrando-se numa formação discursiva que chamamos FDLP: Formação Discursiva Língua-Padrão, em que já se inscrevia o Dicionário de lingüistica e gramática de Mattoso Camara Jr.

O risco para o professor de português - ao se pautar acriticamente nos materiais didáticos, científicos, pedagógicos, metalinguísticos mais indicados, mesmo legítimos, pela tradição universitária e acadêmica - é cair num reprodutivismo que não apenas atinge a produção de conhecimento, a suposta descrição da língua, mas também o aluno diretamente. $\mathrm{Na}$ discussão sobre o certo e o errado (o sexo dos anjos da língua), só uma coisa é certeira: a certeza de que o aluno, tão proficiente em sua "comunicação" quanto qualquer outro (ou seja: exposto a tantos equívocos quanto quaisquer outros sujeitos), tem não apenas sua subjetividade tocada, maltratada pela correlação língua-classe social (que provoca preconceito linguístico), mas também as relações identitárias com sua classe.

Se não é da linguagem dizer tudo, conforme nossa epígrafe de Ferreira Gullar, por que o homem tenta domar a língua(gem) de forma 
a tentar fazê-la se traduzir e dizer suas vontades, ou seja, se ela quer ser assim ou assada, se ela prefere a aparência $\mathrm{Y}$ ou a $\mathrm{Z}$ (para ficar mais bonita e correta)? Não é da língua ser mais bonita que outra língua, tampouco é das variedades linguísticas serem umas melhores que outras.

\section{Referências}

ALCALÁ-RODRÍGUEZ, Carolina. Entre o espaço e seus habitantes. In: ORLANDI, Eni P. (Org.). Para uma enciclopédia da cidade. Campinas: Pontes, Labeurb/Unicamp, 2003.

AGUSTINI, Carmen Lúcia Hernandes. A estilistica no discurso da gramática. Campinas: Pontes; São Paulo: Fapesp, 2004.

AUROUX, Sylvain. A revolução tecnológica da gramatização. Trad. Eni Puccinelli Orlandi. Campinas: Editora da Unicamp, 2001.

AUTHIER-REVUZ, Jacqueline. Palavras incertas: As não-coincidências do dizer. Trad. Claudia R. Castellanos Pfeiffer et al. Campinas: Editora da Unicamp, 1998.

CAMARA JR., Joaquim Mattoso. Dicionário de lingüistica e gramática. 11. ed. Petrópolis: Vozes, 1988.

DIAS, Juciele Pereira. O lugar e o funcionamento do título pela obra de Mattoso Camara. 2009. 94f. Dissertação (Mestrado em Estudos Linguísticos) Universidade Federal de Santa Maria, Santa Maria. 2009.

DIAS, Luiz Francisco. Os sentidos do idioma nacional: as bases enunciativas do nacionalismo lingüístico. Campinas: Pontes, 1996.

GUIMARÃES, Eduardo. História da semântica. Campinas: Pontes, 2004.

MARIANI, Bethania Sampaio Corrêa. Colonizaçãa lingüistica. Campinas: Pontes, 2004. 
MORELLO, Rosangela. A língua portuguesa pelo Brasil. 2001. 163f. Tese (Doutorado em Linguística) - Universidade Estadual de Campinas, Campinas. 2001.

NUNES, José Horta. Dicionários no Brasil: análise e história do século XVI ao XIX. Campinas: Pontes; São Paulo: Fapesp; São José do Rio Preto: Faperp, 2006.

ORLANDI, Eni Puccinelli. A linguagem e seu funcionamento: as formas do discurso. 4. ed. Campinas: Pontes, 1996.

- O que é lingüística. São Paulo: Brasiliense, 1999. (Coleção Primeiros Passos, 184).

- Discurso e texto: formulação e circulação dos sentidos. Campinas: Pontes, 2001.

- Interpretação: autoria, leitura e efeitos do trabalho simbólico. 4. ed. Campinas: Pontes, 2004.

. A língua brasileira. Ciência e Cultura, v. 57, n. 2, abr./jun. 2005. - As formas do silêncio: no movimento dos sentidos. 6. ed. Campinas: Editora da Unicamp, 2007.

PÊCHEUX, Michel. O discurso: estrutura ou acontecimento. 4. ed. Trad. Eni Puccinelli Orlandi. Campinas: Pontes, 2006.

- Semântica e discurso. Trad. Eni P. Orlandi, Lourenço Chacon Jurado Filho, Manoel Luiz Gonçalves Corrêa, Silvana Mabel Serrani. 4. ed. Campinas: Editora da Unicamp, 2009.

.; HAROCHE, Claudine, HENRY, Paul. A semântica e o corte saussuriano: língua, linguagem, discurso. Trad. Roberto Leiser Baronas; Fábio César Montanheiro. Linguasagem, São Carlos, 3 ed., out./nov. 2008. 
VARIAÇÃO LINGUÍSTICA (verb. 1-8). In: Enciclopédia discursiva da cidade. Disponível em: <http://www.labeurb.unicamp.br/endici/>. Acesso em: 13 fev. 2009. [verbetes escritos por Cláudia Pfeiffer]

ZOPPI FONTANA, Mónica Graciela. Identidades (in)formais. Contradição, processos de designação e subjetivação na diferença. Organon (UFRGS), Porto Alegre, v. 17, n. 35, p. 245-282, 2003. 